\title{
Improving Maggot Therapy: Mass Rearing And Molecular Identification of Lucilia Sericata (Meigen, 1826) Larvae In Maggotarium, School of Health, Shiraz
}

\section{Masoumeh Bagheri}

Shiraz University of Medical Sciences

Hamzeh Alipour ( $\square$ hamzehalipour993@yahoo.com )

Shiraz University of Medical Sciences

Marziea Shahriari-Namadi

Shiraz University of Medical Sciences

\section{Seyed Hossein Malekpour}

Shiraz University

\section{Abasali Raz}

Research Associate Professor of Medical Biotechnology Pasteur Institute of Iran.

\section{Research Article}

Keywords: Lucilia, Rearing, C01, Maggot therapy

Posted Date: October 6th, 2021

DOI: https://doi.org/10.21203/rs.3.rs-953241/v1

License: (c) (1) This work is licensed under a Creative Commons Attribution 4.0 International License.

Read Full License 


\section{Abstract}

Background: Lucilia sericata as a member of the family Caliphoridae has a complete metamorphosis. They feed on on necrotic and livingtissues as necrophage species. Sterile larvae of this species has been utilized to heal wounds for decades. The aim of this study were to establish the breeding and identifying of the L.sericata species based on morphological and molecular techniques. Freshly harvested grown under standard conditions in the maggotarium of Health School, Shiraz of. They were screened using conventional morphology, then Primarily, different parameters related to larvae were measured morphologically. Subsequently, DNA was extracted and molecular marker of cytochrome C oxidase (co1) was amplified using PCR assay and sequence data were used for molecular and phylogenetic analysis.

Result: In this study, 50 samples which grown collected from maggotarium were identified as L. sericata using morphological and molecular methods. This species was placed in a separate clade of the phylogenetic tree based on $\mathrm{COI}$ nucleotide sequences of different species and has a phylogenetic similarity to Lucilia purpurascens species of flies.

Conclusion: Larval therapy especially by Lucilia sericata is a promising strategy in wound healing. Due to the importance of larval species in this technique, having an accurate knowledge of aplicable species leads to a proper larval therapy. Increasing in resistance of wounds to antibiotics has led to the use of maggot therapy in the past. Larval therapy is a low-cost, non-surgical way to remove dead tissue (predecessors and necrosis) in chronic wounds and prevents excessive soft tissue damage and infection from reaching the underlying tissues and bones (osteomyelitis). Maggot therapy is a promising way to prevent amputation, especially in people with diabetes.

\section{Introduction}

The Caliphoridae family is one of the largest and most diverse families of flies. Up to 1500 species in 97 genera of this family have been identified so far (1-4), which are distributed in neotropical regions and a large number of them in Africa and southern Europe (5). From Iran, 20 species of three subspecies, Calliphorinae, Chrysomyinae, and Luciliinae have been reported so far (6).

This family have been considered by many researchers in the field of medical sciences, forensic medicine, veterinary medicine, pharmaceutical and biomedicine due to the possibility of easy and fast breeding, ability and growth of this insect on cheap materials, the rapid output of the target product, the non-toxicity of the target product, and the stability of the physiological parameters of the insect during the biotechnology process (7). Also, many studies are still being done on this family (8-10).

Lucilia sericata belongs to the Calliphoridae family (8). This species is mostly distributed in hot and humid regions of the world, although they are also present in areas with dry climates (11). It is a domesticated species and has a high adaptability (12). Lucilia sericata has a complete metamorphosis (Holometaboluse). Life cycle of this species includes egg stages, three larval stages (1, 2, and 3), pupa, and adult. The eggs are placed in clusters of about 2000-3000 on animal carcasses and excrement. 
About 18 to 24 hours later, they will be opened and entered the larval stage. The larvae are milky, conical in shape with anterior and posterior spirals, and after 4 to 5 days, they turn into pupae. Pupae usually have a hard, brown and black coating, and finally, after 6 to 14 days, they turn into adult flies (13). These flies are capable of mass production in the standard environment and conditions of the insectarium. Adults are mostly metallic green. The antenna is tripoded and aristate, and the RS rifle is branched out twice. Frontal sutures are well visible and calypters have been grown well in them. The average lifespan of an adult is usually 7 days (14). One of the nutritional habits is that it feeds on corpse and dead tissues; therefore, it has a special place in medical sciences, veterinary medicine, and forensic medicine $(9,12,15$, 16). One of the useful and practical uses of the larvae of $L$. sericata is in the field of Maggot therapy (17). Maggot therapy is a useful, effective and controlled method using sterile larvae of $L$. sericata to treat a variety of acute and chronic wounds (18). This method was approved by the US FAD in 2004 with the approval of K033391 (19). This method is also used to treat wounds, which are caused by bed sores, traumatic skin injuries, and burns.

It is also effective in chronic diabetic ulcers, osteomyelitis, and ulcers created after cancer surgery (20, 21). Chronic wounds, which are primarily associated with severe and prolonged inflammation, stop the proliferation of cells and cause the extracellular matrix to be regenerated incompletely. Excessive ECM overexpression temporarily and its ineffective removal from the wound surface usually stop the healing of chronic wounds (22). Necrotic tissue is also a good place for the accumulation of various pathogens and the production of biofilms, which in turn cause the infection of dead cells and wounds. $(23,24)$.

Traditional treatments for chronic wounds include surgery, enzymatic debridement, and rinsing (25). The most important drawbacks of these methods are pain, mechanical damage to healthy tissues, and human error. Maggot therapy can be used as an alternative, classical and controlled method instead of the mentioned methods to treat wounds $(26,27)$. Important advantages of this method include cleaning the wound surface, disinfecting and accelerating wound healing (28).The mechanical movement of larvae on the wound and the production and secretion of various digestive enzymes by them are two very important factors in accelerating wound healing (29). Maggot excretions / secretions contain a variety of digestive enzymes, including carboxypeptase A, B (carboxypeptidase A, B), collagenase-amino peptidase (aminopeptidases collagenases), aspirin and serine protease (aspart), trypsin- and chymotrypsin-like ones., and metalloproteases, which are active in a wide range of $\mathrm{pH}$. In larval secretions, by breaking down fibronectin and converting it into biological active components, fibroblasts are multiplied and migrated $(12,30)$. Today, with the advancement of biotechnology, new research is being done on the use of flies products in the pharmaceutical industry, and the production of recombinant proteins from some Lucilia members is being developed and evaluated $(31,32)$. As briefly mentioned above, due to the importance of this species in various fields and sciences, accurate identification of members of this subfamily requires the necessary accuracy and precision. Blow flies have a wide variety of species and their morphological diagnosis is confusing and difficult (31), and due to the similarity of the species, errors in morphological diagnosis may occur. However, the accurate identification of this species of insect can be done by experts and experienced people (33). Due to the importance of accurate identification of species, the use of molecular methods to accurately identify and confirm morphological methods is 
recommended (34). In general, for molecular identification, a variety of nucleotide and mitochondrial loci and different gene markers are used to accurately identify species. The $\mathrm{CO} 1 \mathrm{Cytochrome} \mathrm{c} \mathrm{oxidase} \mathrm{has} \mathrm{a}$ high degree of nucleotide diversity and it is considered by many specialists to identify species. It was first proposed by Harbor and it is well established that this barcode can be used as a suitable marker for identification. Different species of humans, birds, and insects has been considered by many biotechnologists and molecular entomologists as a marker that has been successful in differentiating two species (31). We also decided to use this method to identify the species of Lucilia sericata in the maggotarium of Shiraz School of Health due to the specificity of this marker.

\section{Material And Methods \\ The fly species}

The first $L$. sericata was bought from Shiraz Wound healing and Biotherapy center.

\section{Breading:}

The larvae were transferred to cages $(45 \times 45 \times 45)$ in the Shiraz health school Maggotarium. There were chicken liver and water-sugar inside the cages for flies feeding. The larvae were placed on chicken liver as well as a special container for laying eggs. The eggs were transferred to a new cage. They were exposed to a standard condition; $12-\mathrm{h}$ light/dark cycle with humidity of $40-60 \%$ at $16-25^{\circ} \mathrm{C}$.

\section{Collection and identification:}

50 samples of adult larvae were collected from the cage. ( Fig:1), identified using the morphological identification key and then, they were confirmed by molecular methods.

\section{Molecular methods}

\section{Dna Extraction}

The genomic DNA of samples was extracted using the instructions of the AccuPrep ${ }^{\circledR}$ Genomic DNA Extraction Kit - Bioneer.

\section{Primer Design}

The mRNA sequences of cytochrome oxidase subunit 1 (COI) gene, partial cds, and mitochondrial genes of flies were obtained from the NCBI base gene bank. Then, obtained sequences were entered into the Gene Runner software separately and copied in the MEGA 6.0 software. In this application, they were aligned and based on the conserve points between the compared genes, forward and reverse primers were designed using Oligo7.0 software program and Gene Runner version 4.0 . 
Gene specific forward and reverse primers (GSP) were blasted using NCBI (https://blast.ncbi.nlm.nih.gov/Blast.cgi). The sequence of designed primers is shown in Table 1.

Table 1

The sequence of designed forward and revers primers

\begin{tabular}{|llll|}
\hline Gene & Primer name & $\left.\mathbf{( 5}^{\prime} \mathbf{3}^{\prime}\right)$ Primer sequence & Expected size \\
\hline C01 & Forward & ACTATTAGTAAGAAGAATAG & 300bp \\
\cline { 2 - 3 } & Revers & AAGTTGCAGGAGAGTAGTTG & \\
\hline
\end{tabular}

\section{Polymerase Chain Reaction}

Using Gene runner and Mega 6 software, forward and reverse primers were designed for $\mathrm{CO} 1$ barcode. Primer sequences can be seen in Table 1. Co1 fragment was amplified using pair primer. The PCR reaction volume was $20 \mu \mathrm{l}$ and contained $1 \mu \mathrm{l}$ cDNA, $1 \mu \mathrm{l}$ of pair primer, $10 \mu \mathrm{l}$ master mix and $7 \mu \mathrm{l}$ water. The amplification program included initial denaturation at $95^{\circ} \mathrm{C}$ for $5 \mathrm{~min}$ followed by 35 cycles, including denaturation at $95^{\circ} \mathrm{C}$ for $30 \mathrm{~s}$, annealing at $59^{\circ} \mathrm{C}$ for $30 \mathrm{~s}$, extension at $72^{\circ} \mathrm{C}$ for $80 \mathrm{~s}$, and an additional final extension at $72^{\circ} \mathrm{C}$ for $10 \mathrm{~min}$.

\section{Sequencing}

The products of PCR were purified using Thermo Scientific Gene JET Gel Extraction Kit. The samples were sent to Phishgam Biotech Company in Tehran for sequencing.

\section{Phylogenetic Tree}

Phylogenetic tree based on $\mathrm{COI}$ nucleotide sequences of flies from several worldwide geographical areas, including available data from Gene Bank was constructed by neighbor joining $(\mathrm{NJ})$ method with the Kimura's 2-parmeter model implemented in the MEGA_ version 6.1, and the trees were tested by 1000 bootstrap replicates.

\section{Results}

\section{Morphological Identification}

In the present study, samples were collected from Maggotarium and identified as Lucilia sericata using morphological identification key.

\section{Molecular Identification}


The expected band of $300 \mathrm{bp}$ appeared on the gel (Fig:2). The results of the sequencing (Gel extraction) were blasted on NCBI site, and all samples were identified as Lucilia Sericata.

\section{Phylogenetic Analysis}

In order to analyze and compare, the phylogenetic tree based on $\mathrm{COI}$ nucleotide sequences of different species of flies, their information was registered in the Gene Bank, which was constructed by neighbor joining ( $\mathrm{NJ}$ ) method with the Kimura's 2-parmeter model implemented in the MEGA_version 6.1, and they were tested by 1000 bootstrap replicates (Fig. 3). In the present study, different species such as Lucilia purpurascens, L. papuensis, L. porphyrina, L. illustris, L.sericata, chrysomya rufifacies, Tabanus taeniola, Musca domistica, and Calliphora vicina were compared with our study. Sarcophaga utilis was used as the outgroup of the phylogenetic tree. According to the tree, current study and Lucilia purpurascens the same group and there was a closer relationship between the two species (73 nucliotide). L. papuensis and chrysomya rufifacies are closely related and Tabanus taeniola Will be placed in the next close relationship. L. illustris, L. porphyrina, and Calliphora vicina are also similar and they were placed in a separate subgroup.

L. sericata was clearly separated from them.

\section{Discussion}

In the present study, Lucilia sericata was identified using morphological and molecular methods.

The aim of this study was to identify the morphological and molecular method for identifying Lucilia sericata, and this species was reared on a mass scale in maggotarium at Shiraz School of Health. This species is considered as a suitable model for medical and pharmaceutical research, including the discussion of Maggot therapy. The proteins in larval secretions are now being used both chemically and also in the production of recombinant proteins. Due to the importance of this issue, it is important to accurately identify this species in medical discussions and maggot therapy, which uses sterile larvae of this species to heal wounds.

Temperature and humidity are two important factors in the breeding and growth of insects, including Lucilia, which were raised in the present study with the optimum temperature and humidity of larvae. The larvae were fed using fresh chicken liver and sugar water. In a study, Tachibana ea al. tested artificial diet primarily composed of whole milk powder, dried yeast, and wheat germ in order to compare the lucilia sericata larval diet and its effect on growth and development. They did not observe a significant difference between them on beef liver, although there was a small difference between artificial feeding and longer growth period. Otherwise, there was no difference between the mortality rate and the pupal weight between the artificial meal and the beef liver (35). The results of the present study are consistent with the study of Firoozfar et al (36). 
Using the CO1 marker, we could identify the species Lucilia sericata, and Reibe et al. were able to identify different species with this marker. Six different species was sampled in their study; Calliphora vicina, Calliphora vomitoria, Lucilia caesar, Lucilia sericata, Lucilia illustris, and Protophormia terraenovae(37).

In a study, which conducted by $\mathrm{CHEN}$ et al. in Taiwan, the molecular identification of important species in forensic medicine based on the $\mathrm{CO} 1$ marker was investigated. In this study, species in Taiwan were surveyed from early 2000 and identified using molecular data. Currently, eight species have been identified; Chrysomya megacephala (Fabricius), Chrysomya pinguis (Walker), Chrysomya rufifacies (Macquart), Hemipyrellia ligurriens (Wiedemann), Lucilia bazini Se'guy, Lucilia cuprina (Wiedemann),

Lucilia hainanensis Fan, and Lucilia prophyrina (Walker) $(37,38)$.

Today, due to the development of societies and the increase in accidents and burns, as well as not following a proper diet among people and suffering from diabetes, the wounds, which are caused by these diseases and accidents are spreading. Also, due to the resistance of various bacteria on the wounds to antibiotics, larval therapy is used as a classic and modern method and a supplement to surgical methods. Therefore, accurate knowledge of Lucilia sericata and its use in larval therapy is very important. Sometimes, due to the similarity of some diagnostic characters, this species may be misidentified and the larval therapy may be failed.

\section{Declarations}

\section{Acknowledgments}

In this study, all those who helped in the implementation of this project should be thanked and appreciated. The respected staff of Shiraz Larval Therapy Center, the respected experts of the Insectarium and the laboratory of Shiraz School of Health are thanked. This article is extracted from the first part of the thesis of Ms. Masoumeh Bagheri, PhD student in Vector Biology and Control of Diseases, School of Health, Shiraz University of Medical Sciences, Shiraz, Iran.

\section{Authors' contributions}

$M B$ and HA wrote the main manuscript. MB and MSh performed the experiment. SM and AR reviewed the final revision of the manuscript. All Authors read and approved the manuscript.

\section{Funding}

This experiment was funded by Shiraz University of Medical Sciences.

\section{Availability of data and materials}

The datasets used and analyzed during the present study are available from the corresponding author. 


\section{Ethics approval and consent to participate}

The present research did not require ethical approval.

\section{Consent for publication}

Not applicable.

\section{Competing interests.}

The all authors stated that they have no competing interests in research.

\section{Author details}

${ }^{1}$ Department of Medical Entomology, School of Health, Shiraz University of Medical Sciences, Shiraz, Iran. ${ }^{2}$ Research Center for Health Sciences, Institute of health, Shiraz University of Medical Sciences, Shiraz,Iran. ${ }^{3}$ Department of Pathobiology, Shiraz University, Shiraz, Iran. ${ }^{4}$ Research Associate Professor of Medical Biotechnology Pasteur Institute of Iran.

\section{References}

1. Haglund WD, Sorg MH. Advances in forensic taphonomy: method, theory, and archaeological perspectives: CRC Press; 2001.

2. Rivers DB, Dahlem GA. The science of forensic entomology: John Wiley \& Sons; 2014.

3. Charabidze D, Gosselin M, Hedouin V. Use of necrophagous insects as evidence of cadaver relocation: myth or reality? PeerJ. 2017;5:e3506.

4. Kosmann C, De Mello RP, Souza ÉSH, Luz JRP. A list of current valid blow fly names (Diptera: Calliphoridae) in the Americas South of Mexico with key to the Brazilian species. EntomoBrasilis. 2013;6(1):74-85.

5. Whitworth T. A revision of the neotropical species of Lucilia Robineau-Desvoidy (Diptera: Calliphoridae). Zootaxa. 2014;3810(1):1-76.

6. Modarresi S, Khaghaninia S, Seyyedi Sahebari F. Review of the subfamily Calliphorinae (Dipt.: Calliphoridae) in Iran with two genera and four species as new records. Journal of Insect Biodiversity and Systematics. 2019;5(1):47-57.

7. Yakovlev AY, Kruglikova A, Chernysh S. Calliphoridae flies in medical biotechnology. Entomological Review. 2019;99(3):292-301.

8. Rueda LC, Ortega LG, Segura NA, Acero VM, Bello F. Lucilia sericata strain from Colombia: Experimental colonization, life tables and evaluation of two artifcial diets of the blowfy Lucilia sericata (Meigen)(Diptera: Calliphoridae), Bogotá, Colombia Strain. Biological research. 2010;43(2):197-203. 
9. Anderson M, Kaufman PE. Common Green Bottle Fly or Sheep Blow Fly Lucilia sericata (Meigen) (Insecta: Diptera: Calliphoridae). EDIS. 2011;2011(9).

10. Kotze A, Bagnall N, Ruffell A, Pearson R. Cloning, recombinant expression and inhibitor profiles of dihydrofolate reductase from the Australian sheep blow fly, Lucilia cuprina. Medical and veterinary entomology. 2014;28(3):297-306.

11. Taleb M, Tail G, Açıkgöz HN, Djedouani B, Toumi M. First data on the distribution of Lucilia sericata Meigen, Calliphora vicina Robineau-Desvoidy and Chrysomya albiceps Wiedmann (Diptera, Calliphoridae) in Algeria. Zoology and Ecology. 2018;28(2):142-54.

12. Horobin A, Shakesheff K, Woodrow S, Robinson C, Pritchard D. Maggots and wound healing: an investigation of the effects of secretions from Lucilia sericata larvae upon interactions between human dermal fibroblasts and extracellular matrix components. British Journal of Dermatology. 2003;148(5):923-33.

13. Youssefi M, Rahimi M, Marhaba Z. Occurrence of nasal nosocomial myiasis by Lucilia sericata (Diptera: Calliphoridae) in north of Iran. Iranian journal of parasitology. 2012;7(1):104.

14. Yaghoubi R, Tirgari S, Sina N. HUMAN AURICULAR MYIASIS CAUSED BY LUCILIA SERICATA: CLINICAL AND PARASITOLOGICALCONSIDERATIONS. 2005.

15. Aitken I. Diseases of sheep: John Wiley \& Sons; 2008.

16. Tarone AM, Foran DR. Generalized additive models and Lucilia sericata growth: assessing confidence intervals and error rates in forensic entomology. Journal of forensic sciences. 2008;53(4):942-8.

17. Valachova I, Bohova J, Kozanek M, Takac P, Majtan J. Lucilia sericata medicinal maggots: A new source of antimicrobial compounds. Microbial Pathogens and Strategies for Combating Them: Science, Technology and Education Badajoz, Spain: Formatex Research Center. 2013:1745-53.

18. Cazander G, Pritchard DI, Nigam Y, Jung W, Nibbering PH. Multiple actions of Lucilia sericata larvae in hard-to-heal wounds: larval secretions contain molecules that accelerate wound healing, reduce chronic inflammation and inhibit bacterial infection. Bioessays. 2013;35(12):1083-92.

19. Sherman RA, Cooper EL. Biotherapy: Medicinal maggots and invertebrate immunology from the Clinician's perspective. Advances in Comparative Immunology: Springer; 2018. p. 991-5.

20. Sherman RA, Wyle FA. Low-cost, low-maintenance rearing of maggots in hospitals, clinics, and schools. The American journal of tropical medicine and hygiene. 1996;54(1):38-41.

21. Nigam Y, Dudley E, Bexfield A, Bond AE, Evans J, James J. The physiology of wound healing by the medicinal maggot, Lucilia sericata. Advances in insect physiology. 39: Elsevier; 2010. p. 39-81.

22. Delavary BM, van der Veer WM, van Egmond M, Niessen FB, Beelen RH. Macrophages in skin injury and repair. Immunobiology. 2011;216(7):753-62.

23. Flemming H-C, Wingender J. The biofilm matrix. Nature reviews microbiology. 2010;8(9):623-33.

24. Thurlow LR, Hanke ML, Fritz T, Angle A, Aldrich A, Williams SH, et al. Staphylococcus aureus biofilms prevent macrophage phagocytosis and attenuate inflammation in vivo. The Journal of Immunology. 
2011;186(11):6585-96.

25. Skórkowska-Telichowska K, Czemplik M, Kulma A, Szopa J. The local treatment and available dressings designed for chronic wounds. Journal of the American Academy of Dermatology. 2013;68(4):e117-e26.

26. Schultz GS, Sibbald RG, Falanga V, Ayello EA, Dowsett C, Harding K, et al. Wound bed preparation: a systematic approach to wound management. Wound repair and regeneration. 2003;11:S1-S28.

27. Nigam Y, Bexfield A, Thomas S, Ratcliffe NA. Maggot therapy: the science and implication for CAM Part I-history and bacterial resistance. Evidence-based complementary and Alternative Medicine. 2006;3.

28. Yan L, Chu J, Li M, Wang X, Zong J, Zhang X, et al. Pharmacological properties of the medical maggot: a novel therapy overview. Evidence-Based Complementary and Alternative Medicine. 2018;2018.

29. Choudhary V, Choudhary M, Pandey S, Chauhan VD, Hasnani J. Maggot debridement therapy as primary tool to treat chronic wound of animals. Veterinary world. 2016;9(4):403.

30. Chambers L, Woodrow S, Brown A, Harris P, Phillips D, Hall M, et al. Degradation of extracellular matrix components by defined proteinases from the greenbottle larva Lucilia sericata used for the clinical debridement of non-healing wounds. British Journal of Dermatology. 2003;148(1):14-23.

31. Gottrup F, Jørgensen B. Maggot debridement: an alternative method for debridement. Eplasty. $2011 ; 11$.

32. Hassan MI, Taher FA, Mohamed AF, Kamel MR. Chitosan Nanoparticles Prepared from Lucilia Cuprina Maggots as antibacterial agent. Journal of the Egyptian Society of Parasitology. 2016;46(3):519-26.

33. Jinbo U, Kato T, Ito M. Current progress in DNA barcoding and future implications for entomology. Entomological Science. 2011;14(2):107-24.

34. Sperling FA, Anderson GS, Hickey D. A DNA-based approach to the identification of insect species used for postmorten interval estimation. Journal of Forensic Science. 1994;39(2):418-27.

35. Tachibana S-I, Numata H. An artificial diet for blow fly larvae, Lucilia sericata (Meigen)(Diptera: Calliphoridae). Applied entomology and zoology. 2001;36(4):521-3.

36. Firoozfar F, Moosa-Kazemi H, Baniardalani M, Abolhassani M, Khoobdel M, Rafinejd J. Mass rearing of Lucilia sericata Meigen (Diptera: Calliphoridae). Asian Pacific journal of tropical biomedicine. 2011;1(1):54-6.

37. Reibe S, Schmitz J, Madea B. Molecular identification of forensically important blowfly species (Diptera: Calliphoridae) from Germany. Parasitology research. 2009;106(1):257-61.

38. Chen W-Y, Hung T-H, Shiao S-F. Molecular identification of forensically important blow fly species (Diptera: Calliphoridae) in Taiwan. Journal of Medical Entomology. 2004;41(1):47-57.

\section{Figures}




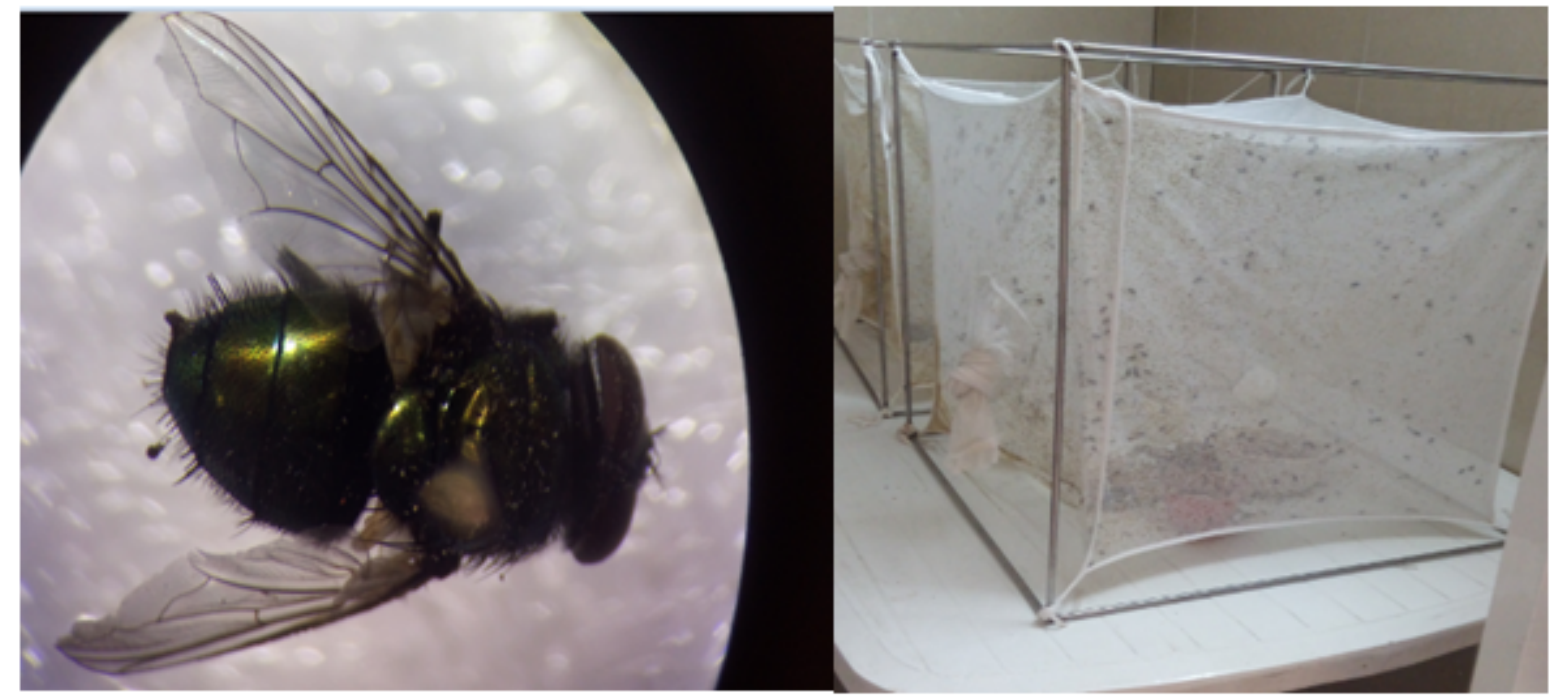

Figure 1

Shiraz Health School Maggotarium

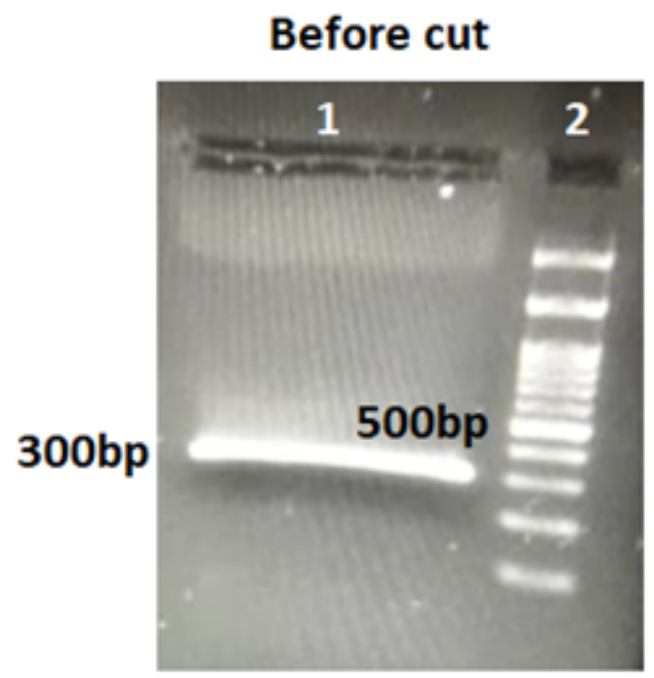

1- DNA

2-Ladder 100bp
After cut

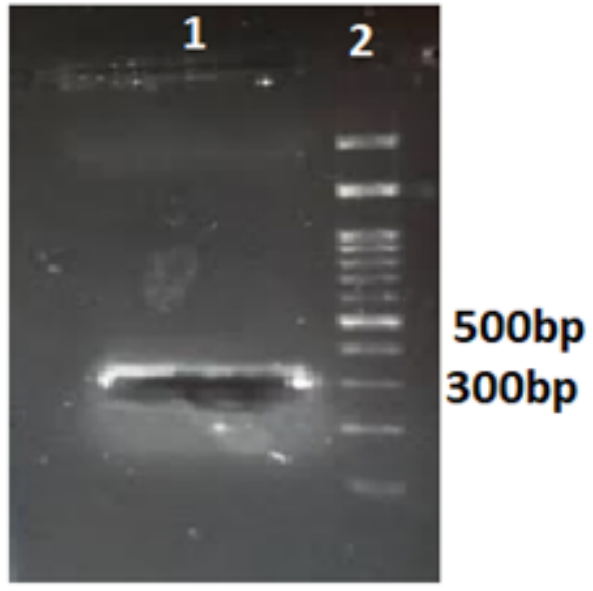

1- DNA

2-Ladder 100bp

Figure 2

Number 1, PCR product of Lucilia sericata (CO1 marker), 300bp band; Number 2: ladder 100. 


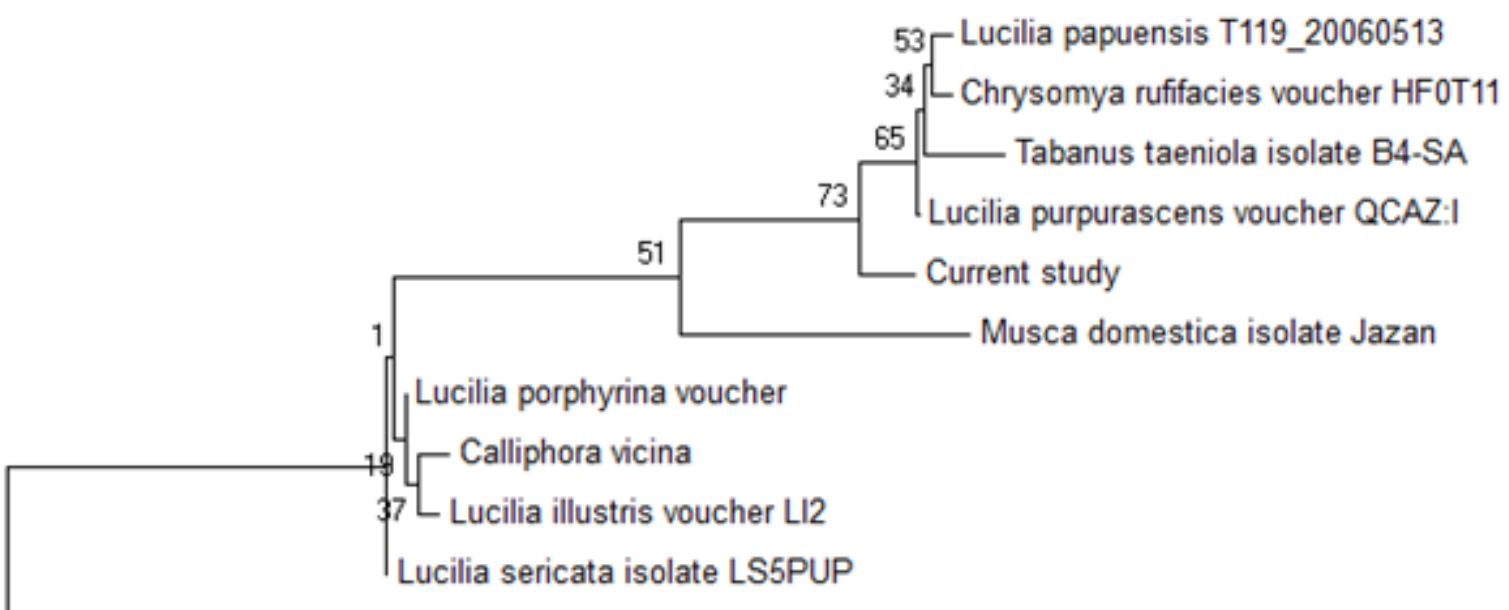

Sarcophaga utilis

\section{Figure 3}

Phylogenetic tree based on $\mathrm{CO} 1$ sequences (Flies) 